Bali Medika Jurnal.

Vol 7 No 1, 2020: 69-76

ISSN : 2615-7047

DOI: https://doi.org/10.36376/bmj.v7i1

Disubmit 27 Maret 2020

Diterima 24 Juli 2020

\title{
PENGARUH LATIHAN HATHA YOGA ERHADAP KUALITAS TIDUR PADA LANSIA
}

\section{EFFECTS OF HATHA YOGA EXERCISE ON SLEEP QUALITY IN THE ELDERLY}

\author{
Nurul Faidah $^{1}$, I Putu Bagus Maha Bindhu', \\ Ni Nyoman Putri Sriadi, Spd Kes, MM $^{3}$ \\ STIKes Wira Medika Bali ${ }^{12}$, RSUD Wangaya ${ }^{3}$
}

\begin{abstract}
ABSTRAK
Proses penuaan banyak mengalami kemunduran fisik maupun mental yang dapat menimbulkan berbagai masalah seperti penurunan kualitas tidur. Salah satu cara meningkatkan kualitas tidur pada lansia adalah dengan melakukan latihan Hatha Yoga. Tujuan penelitian ini untuk mengetahui pengaruh Hatha Yoga terhadap kualitas tidur lansia. Hatha Yoga merupakan salah satu senam ringan yang dapat dilakukan oleh lansia bertujuan menimbulkan efek relaksasi agar dapat meningkatkan kualitas tidur ataupun memperbaiki kualitas tidur agar menjadi lebih baik. Desain penelitian: yang digunakan adalah pra eksperimental dengan One-S.Kep., Ns, M.Kes ${ }^{2}$ group Pre test-Post test Design dan jumlah responden 20 orang. Hasil penelitian menunjukan kualitas tidur sebelum diberikan latihan Hatha Yoga didapatkan hasil rerata kualitas tidur sebesar 7.10 dengan standar deviasi 1.16 dan sesudah diberikan latihan Hatha Yoga didapatkan hasil rerata kualitas tidur sebesar 3.95 dengan standar deviasi 1.31. Berdasarkan analisa data menggunakan uji Wilcoxon Sign Rank Test diperoleh nilai $p$ value $=0,000<\alpha(0.05)$ maka Ho ditolak dan Ha diterima yang artinya terdapat perbedaan yang signifikan kualitas tidur pre dan post test. Jadi, terdapat pengaruh latihan Hatha Yoga terhadap kualitas tidur pada lansia.
\end{abstract}

Kata Kunci : Latihan Hatha Yoga, Kualitas Tidur, Lansia

\begin{abstract}
In elderly aging process many experiencing physical and mental deterioration that can cause various problems such as decreased quality of sleep. One way to improve the quality of sleep in the elderly is to do Hatha Yoga exercises. This study was conducted to determine the effect of Hatha Yoga on sleep quality in elderly. Hatha Yoga is one of the small gymnastics that can be done by elderly aims to cause relaxation effect in order to improve the quality of sleep or improve the quality of sleep to be better. The research design used was pre experimental with One-group Pre test - Post test Design and number of respondents were 20 people. The results showed the quality of sleep before the Hatha Yoga exercise was given the results of the average quality of sleep by 7.10 with a standard deviation of 1.16 and after the Hath Y Yoga exercise was obtained the average sleep quality of 3.95 with a standard deviation of 1.31. Based on data analysis using test Wilcoxon Sign
\end{abstract}


Bali Medika Jurnal.

Vol 7 No 1, 2020: 69-76

ISSN : 2615-7047

DOI: https://doi.org/10.36376/bmj.v7i1

Rank Test obtained $p$ value $=0,000<\alpha(0.05)$ then Ho rejected and Ha accepted which means there are significant differences in quality of pre and post test bed. Thus, there is an effect of Hatha Yoga exercise on sleep quality in the elderly. Based on the results of the study, it is expected that elderly with poor sleep quality in order to carry out Hatha Yoga exercises regularly and continuously.

Keywords: Hatha Yoga Exercise, Sleep Quality, Elderly

Alamat Korespondensi : Jl. Kecak No.9A, Tonja, Kec. Denpasar Utara, Kota Denpasar, Bali 80239 Email : nurulfaidah_wika@yahoo.co.id

\section{PENDAHULUAN}

Proses menua merupakan proses fisiologis yang dialami setiap orang (Waruwu, 2015). Menurut WHO dan Undang-Undang Republik Indonesia Nomor 13 tahun 1998 tentang Kesejahteraan Lanjut Usia pada bab 1 ayat 2, yang dimaksud dengan lanjut usia (lansia) adalah seseorang yang telah mencapai usia 60 tahun keatas (Kushariyadi, 2012).

Jumlah lansia diseluruh dunia diperkirakan melebihi 625 juta jiwa. Pada tahun 2025 lansia akan mencapai 1,2 milyar (Padila, 2013). \%. Provinsi dengan presentase lansia tertinggi adalah DI Yogyakarta $(13,4 \%)$ dan terendah adalah Papua (2,8\%). Sedangkan Bali menempati urutan ke 4 setelah DI Yogyakarta, Jawa Tengah, dan Jawa Timur. Berdasarkan data proyeksi penduduk, diperkirakan tahun 2017 terdapat 23,66 juta jiwa penduduk lansia di Indonesia (9,03\%). Diprediksi jumlah lansia tahun 2020 (27,08 juta), tahun 2025 (33,69 juta) tahun 2030 (40,95 juta) dan tahun 2035 (48,19 juta). Jumlah lansia di Kabupaten Gianyar tahun 2016 berjumlah 50025 jiwa dengan jumlah laki-laki 25621 jiwa dan perempuan 24404 jiwa (Gianyar, 2018). Jumlah Lansia di Desa Medahan, Gianyar sebanyak 701 jiwa dengan jumlah laki-laki 335 jiwa dan perempuan 366 jiwa.

Berbagai masalah yang ditemukan pada lansia yang disebabkan oleh terjadinya kemunduran fisik maupun mental yaitu adalah penurunan kualitas tidur. Perubahan pola tidur pada lansia disebabkan oleh perubahan sistem neurologis yang secara fisiologis akan mengalami penurunan jumlah dan ukuran neuron pada sistem saraf pusat. Hal ini mengakibatkan fungsi dari neurotransmiter pada sistem neurologi menurun, sehingga distribusi norepinefrin yang merupakan zat untuk merangsang tidur juga akan menurun (Potter \& Perry, 2010).

Kualitas tidur adalah suatu keadaan tidur yang dijalani seorang individu menghasilkan kesegaran dan kebugaran saat terbangun. Kualitas tidur mencakup aspek kuantitatif dari tidur, seperti durasi tidur, latensi tidur serta aspek subjektif dari tidur. Adapun upaya yang dapat dilakukan untuk mengatasi gangguan tidur antara lain terapi farmakologi dan terapi nonfarmakologi. Salah satu terapi non farmakologis yaitu dengan melakukan Latihan Hatha Yoga. Yoga merupakan salah satu senam ringan yang dapat dilakukan oleh lansia untuk menimbulkan efek relaksasi agar dapat menambah kualitas tidur ataupun memperbaiki kualitas tidur agar menjadi lebih baik. Saat ini hatha yoga merupakan aliran yang paling popular dibanding aliran yoga lainnya (Kinasih, 2010). Fokus latihan hatha yoga 
meliputi, teknik pranayama (teknik pernafasan), teknik mudra (gestur), banda (kuncian), asana (postur atau gerak olah tubuh), relaksasi, dan meditasi.

Berdasarkan studi pendahuluan yang dilakukan pada tanggal 9 Maret 2018 di Prana Yoga Ananda, Gianyar terhadap 33 lansia dengan metode wawancara menggunakan kuesioner The Pittsburgh Sleep Quality Index (PSQI) didapatkan hasil 30 lansia mengalami gangguan tidur buruk dengan keluhan sulit untuk memulai tidur saat malam hari, sering terbangun dan sulit untuk tertidur kembali.Lansia mengatakan sering terbangun pada malam hari rata-rata 2-3 kali untuk buang air kecil dan setelah itu sulit untuk memulai tidur kembali. Keluhan lain yang disampaikan oleh lansia diantaranya adalah nyeri pada bagian kaki, merasakan gelisah dan mimpi buruk. Rata-rata lansia jarang tidur siang karena faktor pekerjaan, 4 diantara lansia lainnya mengeluh lemas saat bangun di pagi hari, lansia mengatakan tidak ada yang mengkonsumsi obat tidur maupun memeriksakan gangguan tidurnya ke Puskesmas, sedangkan 3 lansia tidak mengalami gangguan tidur atau tanpa keluhan. Hasil wawancara dengan ketua Prana Yoga Ananda, Gianyar belum pernah memberikan Hatha Yoga sebagai alternative untuk meningkatkan kualitas tidur pada lansia yang mengalami ganggun tidur.

Berdasarkan permasalahan dan data diatas peneliti tertarik untuk melakukan penelitian ini karena hatha yoga merupakan salah satu latihan yang bisa meningkatkan kualitas tidur pada lansia sehingga peneliti tertarik meneliti tentang Pengaruh Latihan Hatha Yoga Terhadap Kualitas Tidur pada Lansia.

\section{METODE PENELITIAN}

Metode yang digunakan dalam penelitian ini adalah metode penelitian kuantitatif yang merupakan metode penelitian untuk meneliti populasi atau sampel dengan tujuan untuk menguji hipotesis tertentu yang telah ditentukan (Sugiyono, 2011). Desain penelitian yang digunakan adalah Pra-Experimental dengan menggunakan rancangan One-group pra-post test design yaitu rancangan penelitian yang mengungkapkan hubungan sebab akibat dengan cara melibatkan satu kelompok subjek. Kelompok subjek diobservasi sebelum dilakukan intervensi dan diobservasi kembali setelah intervensi (Nursalam, 2016). Penelitian ini dilakukan di Prana Yoga Ananda, Kabupaten Gianyar. Provinsi Bali waktu yang digunakan empat Mei sampai empat Juni 2018. Penelitian ini perlu dilakukan analisis terhadap data yang dikumpulkan dan mengetahui seberapa besar pengaruh antar variabel yang ada. Data pada penelitian ini dikumpulkan dengan dengan alat ukur The Pittsburgh Sleep Quality Index (PSQI). Besar sampel pada penelitian ini sejumlah 20 orang. Teknik sampling pada penelitian ini ditetapkan secara Non Probability dengan metode Purposive sampling dimana suatu tehnik penetapan sempel dengan cara memilih sampel diantara populasi sesuai dengan yang dikehendaki peneliti. Analisis yang digunakan dalam penelitian ini adalah untuk mengetahui Pengaruh Latihan Hatha Yoga Terhadap Kualitas Tidur Pada Lansia. Hasil pengukuran dalam penelitian ini adalah dengan skala nominal dan interval, sehingga dilakukan uji normalitas menggunakan shaporowilk dan untuk mengetahui Pengaruh Latihan Hatha Yoga Terhadap Kualitas Tidur Pada Lansia dilakukan analisa dengan uji Wilcoxon Sign Rank Test dengan hasil Sig 0,000. 


\section{HASIL DAN PEMBAHASAN}

\section{HASIL}

\section{Karakteristik subyek penelitian}

\section{Usia}

Tabel 1. Distribusi Responden Penelitian Berdasarkan Umur

\begin{tabular}{clcc}
\hline No & Umur & $\begin{array}{c}\text { Frekuensi } \\
\text { (f) }\end{array}$ & Presentase (\%) \\
\hline 1 & $\begin{array}{l}\text { Lanjut usia } \\
(60-74)\end{array}$ & 18 & 90.0 \\
2 & $\begin{array}{l}\text { Lanjut usia } \\
\text { tua (75-90) }\end{array}$ & 2 & 10.0 \\
\hline \multicolumn{2}{c}{ Total } & 20 & 100,0 \\
\hline
\end{tabular}

Berdasarkan tabel 4.1 di atas, dari 20 responden dapat diketahui bahwa karakteristik lansia berdasarkan umur, mayoritas lansia yaitu 18 lansia (90\%) berumur 60-74 tahun.

\section{Pekerjaan}

Tabel 2. Distribusi Responden Penelitian Berdasarkan Pekerjaan

\begin{tabular}{|c|c|c|c|}
\hline No & Pekerjaan & Frekuensi (f) & Presentase $(\%)$ \\
\hline 1 & Petani & 4 & 20.0 \\
\hline 2 & Guru & 2 & 10,0 \\
\hline 3 & Pedagang & 8 & 40.0 \\
\hline 4 & Tidak Bekerja & 6 & 30.0 \\
\hline & Total & 20 & 100.0 \\
\hline
\end{tabular}

Berdasarkan tabel 4.2 diatas, dari 20 responden yang diteliti mayoritas lansia yaitu 8 orang (40\%) adalah pedagang.

3. Jenis Kelamin

Table 3. Distribusi Responden Penelitian Berdasarkan Jenis Kelamin

\begin{tabular}{clcc}
\hline No & Jenis Kelamin & Frekuensi (f) & Presentase (\%) \\
\hline 1 & Laki-laki & 8 & 40.0 \\
2 & Perempuan & 12 & 60.0 \\
\hline & & 15 & 100.0 \\
\hline
\end{tabular}

Berdasarkan tabel 4.3 diatas, dari 20 responden yang diteliti mayoritas yaitu 12 orang $(60 \%)$ perempuan. 
Bali Medika Jurnal.

Vol 7 No 1, 2020: 69-76

ISSN : 2615-7047

DOI: https://doi.org/10.36376/bmj.v7i1

\section{Hasil Pengamatan terhadap Objek Penelitian Berdasarkan Variabel Penelitian}

Tingkat kualitas tidur sebelum diberikan hatha yoga

\begin{tabular}{lcc}
\hline & \multicolumn{2}{c}{ Tingkat kualitas tidur sebelum diberikan hatha yoga } \\
\cline { 2 - 3 } & Hasil Pretest kualitas tidur & Hasil Posttest kualitas tidur \\
\hline Mean & 7.10 & 3.95 \\
\hline Std. & 1.16 & 1.31 \\
Deviation & & \\
\hline Min & 6.00 & 3.00 \\
\hline Max & 10.00 & 8.00 \\
\hline
\end{tabular}

Berdasarkan tabel distribusi frekuensi tingkat kualitas tidur sebelum diberikan latiha Hatha Yoga di atas dapat diketahui pretest didapatkan hasil rerata kualitas tidur sebesar 7.10 dengan standar deviasi 1.16. Tingkat kualitas tidur setelah diberikan latihan Hatha Yoga didapatkan hasil rerata kualitas tidur sebesar 3.95 dengan standar deviasi 1.31 .

\section{Hasil Analisa Data}

1. Hasil analisis

Table 4. Pengaruh Latihan Hatha Yoga Terhadap Kualitas Tidur pada Lansia

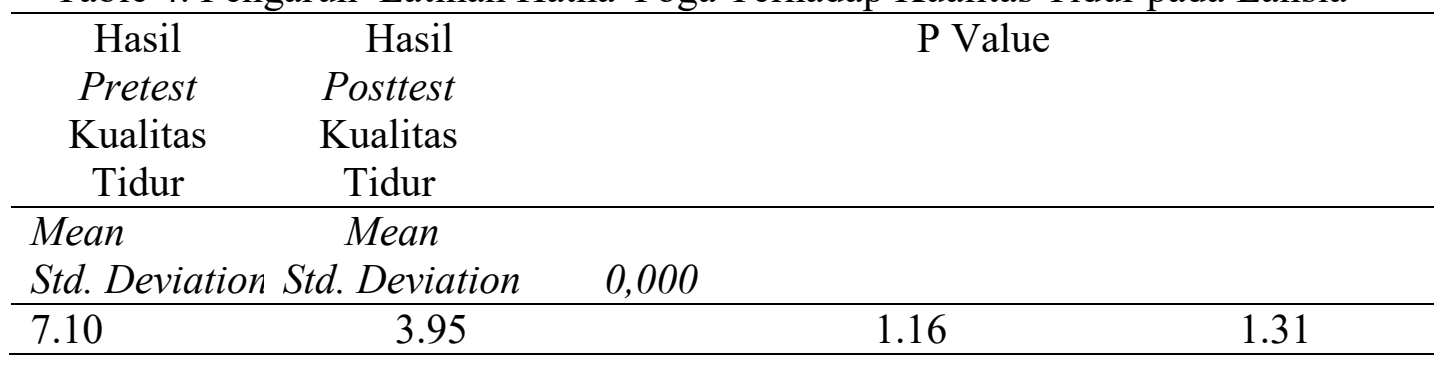

Berdasarkan tabel diatas dapat dilihat bahwa terjadi peningkatan kualitas tidur pada lansia sesudah diberikan latihan Hatha Yoga. Dari hasil uji Wilcoxon Sign Rank Test diperoleh nilai $p$ value $=0,000<\alpha(0.05)$ maka Ho ditolak dan Ha diterima yang artinya terdapat pengaruh yang signifikan kualitas tidur pre dan post test. Jadi, terdapat pengaruh latihan Hatha Yoga terhadap peningkatan kualitas tidur pada lansia.

\section{PEMBAHASAN}

Hasil penelitian latihan Hatha Yoga di Prana Yoga Ananda Kabupaten Gianyar Provinsi Bali pada pretest didapatkan hasil rerata kualitas tidur sebesar 7.10 dengan standar deviasi 1.16. Hasil penelitian yang didapatkan menunjukkan lansia sebelum diberikan latihan Hatha Yoga rerata mengalami tingkat kualitas tidur buruk.

Hasil penelitian ini didukung oleh penelitian yang dilakukan oleh Suryadi (2016) yang meneliti tentang pengaruh senam ergonomis terhadap kualitas tidur lansia di Puskesmas Kota Wilayah Selatan Kediri. Dimana lansia yang menjadi responden setelah diukur menggunakan kuesioner Pittsburgh Sleep Quality Index 
(PSQI) didapatkan rerata kualitas tidur 7.50. Jadi tidak ditemukan lansia yang mengalami kualitas tidur baik. Pada hasil post test didapatkan hasil rerata kualitas tidur sebesar 3.95 dengan standar deviasi 1.31. Hasil tersebut menunjukan bahwa rerata nilai kualitas tidur mengalami peningkatan dari sebelumnya setelah diberikan Hatha Yoga.

Hatha Yoga merupakan salah satu senam ringan yang dapat dilakukan oleh lansia untuk menimbulkan efek relaksasi agar dapat menambah kualitas tidur ataupun memperbaiki kualitas tidur agar menjadi lebih baik. Hatha Yoga adalah tujuan yang sistematik komprehensif untuk pencapaian fisik, psikologis, spiritual kesehatan dan kesejahteraan, dan menggabungkan beberapa variasi postural/latihan, pernapasan, dan meditasi. Hatha Yoga mampu mengembalikan posisi dan kelenturan sistem saraf dan aliran darah yang sangat baik untuk lansia. Hatta yoga mampu memaksimalkan asupan oksigen ke otak, mampu menjaga sistem kesegaran tubuh serta sistem pembuangan energi negatif dari dalam tubuh. Peningkatan oksigen didalam otak akan merangsang peningkatan sekresi norepinefrin yang dapat membuat tubuh menjadi tenang dan lebih mudah untuk tidur yang sekaligus dapat memperbaiki siklus dan pola tidur lansia. Kombinasi hatha yoga yang lembut dan restoratif dapat memberikan manfaat yang efektif untuk meningkatkan tidur (Mustian, 2014).

Retikuler Aktivating System (RAS) juga dapat memberikan rangsangan visual, pendengaran, nyeri, dan perabaan yang dapat menerima stimulus dari korteks serebri termasuk rangsangan emosi dan proses pikir, dalam keadaan sadar, neuron dalam RAS akan melepaskan katekolamin seperti norepenepri sel khusus yang berada di pons dan batang otak tengah, yaitu Bulber Syncrhonozing Region (BSR), sedangkan bangun tergantung keseimbangan implus yang diterima dipusat otak dan sistem limbic, dengan demikian sistem pada batang otak yang mengatur siklus atau perubahan dalam tidur adalah RAS dan BSR (Aziz, 2008 dalam Aspiani, 2014).

Peningkatan kualitas tidur lansia yang diberikan perlakuan latihan Hatha Yoga karana Hatha Yoga mampu menimbulkan efek relaksasi. Hatha yoga mampu memaksimalkan asupan oksigen ke otak, mampu menjaga sistem kesegaran tubuh serta sistem pembuangan energi negatif dari dalam tubuh. Peningkatan oksigen didalam otak akan merangsang peningkatan sekresi norepinefrin yang dapat membuat tubuh menjadi tenang dan lebih mudah untuk tidur yang sekaligus dapat memperbaiki siklus dan pola tidur lansia. Latihan berupa Hatha Yoga yang dilakukan selama 60 menit 2 kali seminggu. Pemberian Hatha Yoga dapat meningkatkan kebutuhan tidur secara kuantitas, peningktakan kebutuhan tidur secara kuantitas tersebut dapat disebabkan karana Hatha Yoga merupakan salah satu latihan fisik yang menenangkan dengan menerapkan latihan pernafasan dan tehnik relaksasi. Latihan relaksasi dapat digunakan untuk memasuki kondisi tidur karena dengan mengendorkan otot secara sengaja akan membentuk suasana tenang dan santai dimana suasana tenang dan santai diperlukan seseorang untuk memulai tidur, selain itu Hatha Yoga dapat meningkatkan kebugaran fisik, psikologi, spiritual, kesehatan jantung lansia sehingga akan meningkatkan kualitas hidup, menurunkan kecemasan dan meningkatkan kebugaran fisik sehingga dapat meningkatkan kualitas tidur.

Latihan Hatha Yoga merangsang penurunan aktifitas saraf simpatis dan peningkatan aktifitas saraf para simpatis yang berpengaruh pada penurunan hormon 
adrenalin, norepinefrin dan katekolamin serta vasodilatasi pada pembuluh darah yang mengakibatkan transport oksigen keseluruh tubuh terutama otak lancar sehingga dapat menurunkan tekanan darah dan nadi menjadi normal. Pada kondisi ini akan meningkatkan relaksasi lansia. Selain itu, sekresi melatonin yang optimal dan pengaruh beta endorphin dan membantu peningkatan pemenuhan kebutuhan tidur lansia. Peningkatan kualitas dan kuantitas pemenuhan kebutuhan tidur juga akan mempengaruhi tekanan darah dan nadi untuk tetap dalam batas normal ketika lansia bangun tidur.

\section{Simpulan}

\section{SIMPULAN DAN SARAN}

Hasil penelitian sebelum diberikan latihan Hatha Yoga didapatkan hasil pretest didapatkan hasil rerata kualitas tidur sebesar 7.10 yang masuk dalam kualitas tidur buruk. Setelah diberikan latihan Hatha Yoga didapatkan hasil posttest didapatkan hasil rerata kualitas tidur sebesar 3.95 yang masuk kualitas tidur baik. Jadi, terdapat pengaruh latihan Hatha Yoga terhadap peningkatan kualitas tidur pada lansia. Hatha Yoga dapat meningkatkan kebugaran fisik, psikologi, spiritual, kesehatan jantung lansia sehingga akan meningkatkan kualitas hidup, menurunkan kecemasan dan meningkatkan kebugaran fisik sehingga dapat meningkatkan kualitas tidurPeningkatan kualitas dan kuantitas pemenuhan kebutuhan tidur juga akan mempengaruhi tekanan darah dan nadi untuk tetap dalam batas normal ketika lansia bangun tidur.

\section{Saran}

Berdasarkan hasil penelitian terhadap responden maka penulis menyarankan sebagai berikut untuk lanjut usia hendaknya dengan aktif melaksanakan latihan Hatha Yoga seperti yang sudah diajarkan. Latihan Hatha Yoga hendaknya dilakukan secara rutin 2 kali dalam seminggu sehingga lansia dapat merasakan manfaat secara maksimal. untuk fasilitas pelayanan kesehatan latihan hata yoga dapat dijadikan pedoman dalam meningkatkan kualitas tidur pada lansia atau dapat dipromosikan sebagai program puskesmas maupun rumah sakit melalui kegitan latihan Hatha Yoga. Sedangkan Bagi peneliti selanjutnya penelitian ini dapat digunakan sebagai bahan acuan untuk melakukan penelitian yang lebih spesifik terkait latihan Hatha Yoga terhadap peningkatan kualitas tidur pada lansia atau dapat dikembangkan dengan variable yang dapat mempengaruhi kualitas tidur pada lansia.

\section{DAFTAR PUSTAKA}

Aspiani, R. Y. (2014). Buku Ajar Asuhan Keperawatan Gerontik (Vol. 2). Trans Info Media.

Gianyar, D. K. K. (2018). Profil Kesehatan Kabupaten Gianyar. Dinas Kesehatan. Kinasih, A. S. (2010). Pengaruh latihan yoga terhadap peningkatan kualitas hidup. Buletin Psikologi, 18(1).

Kushariyadi. (2012). Asuhan Keperawatan dan Klien Lanjut Usia. salemba medika. Mustian, K. M. (2014). Yoga as treatment for insomnia among cancer patients and 
Bali Medika Jurnal.

Vol 7 No 1, 2020: 69-76

ISSN : 2615-7047

DOI: https://doi.org/10.36376/bmj.v7i1

survivors: a systematic review. European Medical Journal. Oncology, 1, 106.

Nursalam. (2016). Metodelogi Penelitian Ilmu Keperawatan Pendekatan Praktis Edisi 4. salemba medika.

Padila. (2013). Asuhan Keperawatan Penyakit Dalam. EGC.

Potter, \& Perry. (2010). Buku Ajar Fundamental Keperawatan: Konsep, Proses dan Praktik (4th ed.). EGC.

Sugiyono. (2011). Metode penelitian kuantitatif dan kualitatif dan R\&D. Alfabeta. Waruwu, S. (2015). Pengaruh Senam Otak Terhadap Fungsi Kognitif Dan Kualitas Tidur Pada Lansia Di Puskesmas Rantang. 